\title{
On the Production of Synonyms by Arabic-Speaking EFL Learners
}

\author{
Majed Alanazi ${ }^{1}$ \\ ${ }^{1}$ Bangor University, UK \\ Correspondence: Majed Alanazi, Building 7043, P. O. Box 47312, Tabuk, Kingdom of Saudi Arabia. Tel: \\ 966-5-5062-0058. E-mail: majedlinguist@gmail.com
}

Received: December 16, 2016 Accepted: January 11, 2017 Online Published: February 9, 2017

doi:10.5539/ijel.v7n3p17

URL: http://dx.doi.org/10.5539/ijel.v7n3p17

\begin{abstract}
This study examines the productive knowledge of synonyms in English by 40 Saudi EFL learners. It also tests whether the participants' English proficiency level plays a role in their production of English synonyms. To this end, the researcher designed a translation test to measure Saudi EFL learners' ability to produce the correct synonym in contextualised English sentences. In order to test whether the English proficiency level of the participants influenced their production of English synonyms, the participants were divided, on the basis of their scores on the Oxford Placement Test, into two groups: 20 Advanced Learners (ALs) and 20 Intermediate Learners (ILs). The answers of the two groups on the translation test, i.e., the ALs and ILs were compared to check whether their English proficiency level played a role on their answers. A Chi-square test was employed to determine whether the differences between the ALs and ILs on the test were statistically significant. The results show that the number of correct answers provided by ALs was higher than that provided by ILs, suggesting that their English proficiency level may have played a role in their answers. The study suggested that the main sources of error were L1 interference, lack of focus on the acquisition of vocabulary in schools in Saudi Arabia, lack of knowledge of some English lexical items, lack of awareness of the different nuances of meaning between the synonyms in English and lack of knowledge with English collocations. Finally, the study concludes with some recommendations for further research.
\end{abstract}

Keywords: semantics, second language acquisition, translation, synonyms, Arabic-speaking EFL learners

\section{Introduction}

According to Saeed (2003), synonymy can be defined as a kind of sense relationship between words, in which such words exhibit similar basic senses. Cruse (1986, p. 270) states that "natural languages abhor absolute synonyms just as nature abhors a vacuum". However, Edmonds \& Hirst (2002) maintain that there are two types of synonyms, namely, complete and partial synonyms. Complete synonyms have identical senses, while partial synonyms share most of their meaning components (Quine, 1951). Another difference between these two types is that the former do not exist due to the fact that the meanings of words found either in monolingual or multilingual contexts are always changing (Quine, 1951). In addition, cases of semi-synonymy or partial-synonymy can be related to dialectal variations and technical terms, e.g., underwear (AmE) vs. pants (BrE); groundhog vs. woodchuck; plesionym vs. near-synonym (Edmonds \& Hirst 2002, p. 107). However, these words still change the style of an utterance when they are intersubstituted. In other words, despite the closeness in meanings, synonyms have subtle distinguished meanings and are not completely interchangeable (Edmonds \& Hirst ibid). Indeed, many examples of near-synonyms can be detected in language and are easy to find. For instance, lie, falsehood, untruth, fib, and misrepresentation are near-synonyms of one another. Although they denote a statement that does not conform to the truth, they are still different from one another in some aspects of their denotation. Specifically, while a misrepresentation can come about from a misplacement of emphasis, and is not necessarily a deliberate and direct deviation from the truth, a lie is indeed deliberate and direct. While $a$ fib is also an intentional falsification, it is more trivial in nature than a lie, perhaps fabricated to save face (Edmonds \& Hirst ibid). Finally, an untruth is not necessarily told to deceive, but is more likely told out of pure ignorance (Gove, 1984). It has been noted that the production of synonyms is a stumbling block for ESL/EFL learners (Martin, 1984; Hatch \& Brown, 1995; Yeh et al., 2007; Liu, 2013; Liu \& Zhong, 2014; among others). This may indicate that acquiring synonymy is an important skill in L2 contexts. According to Engber (1995), when students learn the semantic differences between the lexical items they choose to communicate with verbally or in writing, their academic work improves remarkably, especially their essays. The findings of Engber's study 
indicate that the quality of the essays produced by L2 students improved due to the diversity of lexical items used in their essays and how each word has been used in its correct context. Based on my experience as an English teacher, synonymy is quite neglected in English language teaching in Saudi Arabia. The production of English synonyms by Arabic-speaking EFL learners, in general, and Saudi EFL learners in particular, has not yet been given due attention. Thus, this study aims to examine the production of English synonyms by Saudi EFL learners using a translation test. It also investigates the extent to which the English proficiency of Saudi EFL learners influences their production of synonyms.

\section{Literature Review}

\subsection{Vocabulary Acquisition Theories}

L2 learners encounter various challenges in SLA. Beardsmore (1982) explains that many challenges faced by L2 learners when they learn the phonology, vocabulary and grammar of L2 are caused by interference habits from their first language (L1). Specifically, the formal elements of L1 can be used in L2, which results in errors in L2, especially when the structure of L1 and L2 are different (Zibin \& Altakhaineh, 2016). When accounting for the errors produced by L2 learners, the researcher needs to take L1 interference into account. Learners have been found to exhibit lexical interference on similar items (Albert \& Obler, 1978). Thus, learners who are learning languages that are structurally the same exhibit mutual interference in comparison to languages that have fewer similar properties and structure. Even if the two languages are structurally similar, learning difficulties can also be detected when the learner attempts to learn features that are different from L1. This is due to the fact that the learner would face more challenges, attempting to learn new items and new usages (Dordick, 1996). However, Dechert (1983) argues that when the two languages, i.e., L1 and L2 are different, learners are more likely to produce errors in L2 which have traces of L1 structures. However, in both cases, L1 interference is caused by a strategy followed by the learner in which he/she assumes that both languages are equivalent and the rules which he/she already knows about L1 can also be used in L2, resulting in erroneous responses. This type of error is usually produced by learners with low or intermediate language proficiency levels, as they are not aware of the differences that may exist between L1 and L2. On the other hand, advanced L2 learners may not produce such errors, since they know that the rules that apply to L1 may not apply to L2.

In a similar vein, Erdoğan (2005, p. 265) suggests that L2 learners' errors can be divided into two main types: interlingual transfer and intralingual transfer. The former results from L1 interference, whereas the latter is caused by partial learning of L2 (see Saville-Troike, 2012). An example of interlingual transfer is detected in the sentence "I'm in your service" as a translation of the Arabic sentence ?ana fi: xidmatak "I'm in your service" in spoken Arabic, rather than the correct sentence, i.e., "I'm at your service". Conversely, attaching the regular plural suffix -s to all nouns in English is an instance of intralingual transfer, as in foots and gooses. This example could have resulted from lack of knowledge of English plural markers and the fact that there are two types of plural markers in English, regular and irregular. With regard to vocabulary acquisition, in general, and synonyms acquisition in particular, interlingual transfer plays a crucial role, especially in the acquisition of collocations (e.g., Yamashita \& Jiang, 2010; Alotaibi, 2014) and synonyms (Liu \& Zhong, 2014). Yamashita \& Jiang (2010) argue that the flexibility of collocations' component words and their cross-linguistic nature have important consequences for learning. That is, their flexibility (i.e., the fact that some words are not strict about the words that accompany them, e.g., heavy not only collocates with traffic, but also with stone and smoker) makes them less obvious as multi-word expressions (Yamashita \& Jiang, 2010, p. 649). This may lead L2 learners to treat collocations as regular phrases unintentionally; hence, they do not learn their specific combination of lexical words (Yamashita \& Jiang, 2010). Consequently, L2 learners may not pay attention to the lexical components of collocations, encouraging them to combine words more liberally. Their unique features also make collocations a potential source of L1 transfer. That is, when L2 learners encounter a new collocation for the first time, they understand its meaning directly in the case of congruent collocation (those that share the same lexical components in L1 and L2), especially when these words are known to them. Conversely, incongruent collocations (those involving different words) could be quite difficult to learn (Yamashita \& Jiang, 2010). Similarly, in his study, Alotaibi (2014) examines the acquisition of lexical collocations by Kuwaiti EFL learners, testing whether the participants' English proficiency level plays a role in their comprehension and use of lexical collocations in English. The results of the study reveal that the participants' had little awareness of lexical collocations in English. There were differences between the participants' results, in that, the advanced learners achieved higher results than the intermediate learners on the test, but the differences between the two groups were not statistically significant. Similar to Yamashita \& Jiang's (2010) results, Alotaibi (2014) proposes that L1 interference played a major role in the participants' erroneous responses (cf. Zibin \& Altakhaineh, 2016). The participants translated the English sentences literally from Arabic, producing incorrect answers. For instance, due 
to L1 interference, the participants chose did a mistake rather than made a mistake on the multiple-choice test, since they translated the collocation directly from Arabic, i.e., sawwa ralat "did a mistake" (Alotaibi, 2014, p. 8). As far as synonyms are concerned, Liu \& Zhong (2014) explain that L2 learners encountered problems with synonyms due to, in part, L1 interference, given that synonyms especially those that involve collocations differ cross-linguistically.

Sadoski (2005) explains that there are two primary sources of effective vocabulary acquisition, namely, direct vocabulary instruction and incidental learning from context. The former refers to systematic explanation and demonstration of ways used to determine the meanings of words unknown to the learners, while the latter refers to the learning that happens incidentally without an intention to learn (Lyster, 2007, p. 27). The reason for such a view could be accounted for by the fact that input-oriented language acquisition theory suggests that if the input is meaningful and contextualised, the learner can connect the meaning with the form (Min, 2008). Consequently, according to Krashen (2004), vocabulary ought to be acquired indirectly or incidentally via extensive reading. However, L2 learners need to have a base vocabulary size before they can acquire vocabulary successfully via extensive reading (Nation \& Waring, 1997). Researchers differ on the base vocabulary size; Hu \& Nation (2000) posit that the base should be 8000-9000 word families, whereas others such as Nation \& Waring (1997) propose that it should be 3000-5000 words. One also needs to pay attention to the goal of the tasks performed in incidental learning tasks, if it is reading comprehension, then vocabulary retention will be very low. According to Coady (1993), the possibility that a word is learned from first exposure is from $5 \%$ to $15 \%$. Thus, repetition is necessary for vocabulary retention in L2 contexts. Even though incidental vocabulary learning is quite useful and has a positive impact on L2 vocabulary repertoire, direct vocabulary instruction is more effective in vocabulary acquisition (Schmitt, 2008). With regard to advanced L2 learners, intentional vocabulary instruction was found to be more beneficial (Lightbown \& Spada, 1999). Those learners have the intension of increasing their vocabulary; hence, the effectiveness of the teaching method.

\subsection{Previous Studies on the Acquisition of Synonyms by EFL learners}

One of the most significant studies on the acquisition of synonyms was conducted by Martin (1984). In his study, he investigates the problems encountered by advanced L2 learners in using synonyms in L2 contexts. Taking into account examples of errors produced by these learners, the results of his study demonstrate that four types were produced: "stylistic, syntactic, collocational, and semantic" (Martin, 1984, p. 130). Martin (1984, p. 131) indicates that stylistic errors are common in L2 contexts and that they are often a result of a mismatch of styles. For instance, learners may use a hyperformal expression instead of an informal one. Or learners may use a word which is too colloquial or too formal in a particular communicative context. Syntactic errors are also quite common among EFL learners. For instance, if learners were provided with the word worship as a general expression for pray, they may produce a syntactic error. In particular, these learners may attach the same preposition that often appears with the familiar word, e.g., pray, to the new synonym, which results in expressions like worshipping to God (Martin, 1984, p. 132). Pertaining to collocational errors are concerned, Martin posits that these types of errors are very difficult owing to their arbitrariness. For example, one can say $a$ big eater but a heavy smoker, loud noise but $a$ strong odour. Finally, the last type of error put forward by Martin (1984) is semantic errors. He indicates that semantic errors are the most difficult type. The subtle difference between the senses of words can make it more challenging for L2 learners to make a distinction between the different synonyms. For instance, damage only takes inanimate objects, whereas injure takes animate objects, e.g., she was badly damaged in the car accident (Martin, 1984, p. 131). Thus, L2 teachers need to pay more attention to the last type since it presents a challenge to ESL/EFL learners.

In the context of L2 acquisition of synonyms, some researchers put special emphasis on the difficulty learners' encounter when they were provided with new synonyms at the same time, indicating that interference effects were detected, making the acquisition of synonyms more challenging (Liu, 2013). As a result, these researchers propose that the learners need to be presented with words that belong to one theme, rather than those that do not for the acquisition to be effective. The differences between these words ought to be explained to the students to enhance their diction and communication skills. Webb (2007) has raised another issue that needs to be taken into consideration if a researcher intends to conduct a study on the effect of known synonyms on the acquisition of unknown ones. Specifically, Webb explains that when a learner has knowledge of a word that is used very frequently, this knowledge can be positively transferred to the unknown word, which may lessen the cognitive burden of processing. The effect one synonym can have on another one is an interesting area to examine. I have noticed, for instance, that learners sometimes refuse to learn a synonym of a certain word, because such knowledge can put more pressure on their ability to retrieve the word when they need it. Thus, in certain cases, learners opt for learning one word instead of two or three that share a similar meaning. This choice differs in 
terms of the learner's English proficiency level. In particular, some learners who have an advanced English proficiency level attempt to learn more vocabulary to sound more native-like. Hence, they are more eager to learn new synonyms and how each one of them is used. In contrast, learners of low or intermediate levels feel that if they know one word with a certain meaning, it would be sufficient for them to communicate with native speakers.

Even though the translation of lexical items from one language into another has been discussed in the relevant literature (e.g., Alharthi, 2014; Alrishan \& Smadi, 2015), no study has examined the translation of synonyms. In their study, Alrishan \& Smadi (2015) investigated the ability of Jordanian EFL learners (i.e., M.A translation students at Yarmouk University and the University of Jordan) to translate idioms from English to Arabic. Even though the English proficiency level of the participants is very high, they encountered difficulties in translating some lexical components of the idioms, or they failed to provide a correct equivalent of the English idiom in Arabic. The main reason for the participants' poor performance was L1 influence, where the participants used their L1 knowledge to translate English lexical expressions. Lack of familiarity with certain items and lack of awareness of the target culture also had an impact on the participants' ability to provide correct translations of the English lexical items. These results may suggest that translation tasks are problematic and challenging to EFL learners, regardless of their English proficiency level. Other researchers such Alharthi (2014) argue that translation does not improve vocabulary retention by EFL learners. Specifically, the findings of his study demonstrate that repeating an English item with its Arabic translation has resulted in more attrition in receptive word knowledge. This strategy encouraged EFL learners to think in Arabic, rather than English, which means that they are less likely to pay attention to lexical items in English and just focus on the Arabic translation. On the other hand, Alharthi (2014) argue that note-taking strategies, which involve writing an English item with its synonym and definition enhanced EFL learners' retention of vocabulary, since it encouraged EFL learners to become more acquainted with lexical items in English.

Taking into account the above literature, one may notice that synonyms are very important for effective communication in L2. I $t$ has also become clear that it is quite problematic for EFL learners. Many studies have focused on the acquisition of different lexical phenomena by Arabic-speaking EFL learners (e.g., Altakhaineh \& Zibin, 2014; Altakhaineh \& Rahrouh, 2015). Nevertheless, no study that tackles the production of English synonyms by Arabic-speaking EFL learners, in general, or Saudi EFL learners, in particular, has been conducted. Hence, investigating the productive skills of EFL learners pertaining to English synonyms can potentially contribute to the fields of lexical semantics and Second Language Acquisition (SLA). Therefore, this study can provide more insight on how L1 can impact the production of L2 synonyms. In particular, the present study aims to provide answers to the following research questions:

(1) To what extent do 40 Saudi EFL learners are able to produce English synonyms?

(2) Do the IL learners produce more errors in the translation task than the AL learners?

(3) Does the English proficiency level of the participants influence their ability to produce synonyms in English?

(4) What type of errors do the participants produce on the translation test?

The next section discusses the methodology followed in the current study.

\section{Methodology}

\subsection{The Participants}

Forty university students, majoring in English, at University of Tabuk, Saudi Arabia participated in the present study. These participants were all native speakers of Saudi Arabic (SA), who had a working knowledge of Modern Standard Arabic (MSA) and their mean age was 23. In order to validate the results, the participants who took part in the current study were selected randomly from the population of students majoring in English at Tabuk University. In addition, the participants were divided based on their English proficiency level into two groups: 20 Intermediate Learners (ILs) and 20 Advanced Learners (ALs). These participants were divided into two groups based on their scores on the Oxford Placement Test (OPT). In particular, if the participants' scores were between 60-79, they were regarded as intermediate, while if their scores were between 80-100+, they were considered advanced. Subsequently, the participants were asked to take a translation test in order to investigate their production of English synonyms (see Appendix A). In addition, in order to ascertain that the synonyms employed in the current study are used in contemporary speech, the frequency of the selected synonyms was checked in the Corpus of Contemporary American English (COCA). 


\subsection{The Test}

A translation test, consisting of 12 sentences, was used to determine whether the participants are able to produce the correct synonym in English as a translation of the Arabic synonym. With regard to the sentences used on the test, they were adapted from COCA and Cambridge Online Dictionary. An example of an item in the translation test used in the current study is provided below (see Appendix A):

يعتبر الاكتئاب من الأسباب الرئيسية التي تدفع الناس للانتحار

Depression is one of the main reasons that drive people to commit suicide.

In the above sentence, the correct translation reflects the participants' ability to recognise lexical items and understand their meanings and then choose the correct synonym in English as a translation of the Arabic synonyms. Note that three cases of each syntactic category of the synonyms are employed in the test; three sets of nouns, three sets of verbs, three sets of adjectives and three sets of adverbs. For example, erroneously/incorrectly/mistakenly is a case of an adverb set. The reason for including these parts of speech is that some studies in the relevant literature focus on synonymous adjectives and verbs more than on English synonymous nouns and adverbs. Thus, this study aims to provide a more comprehensive picture of the production of synonyms via studying all four syntactic categories of the synonymous words. The grading of the test was done by the researcher and another postgraduate student majoring in translation in order to ensure the objectivity of the marking process and to accurately evaluate whether the participants' answers were correct.

\subsection{Data Analysis}

In order to determine whether the differences between the answers of the ALs and ILs were statistically significant, a Chi-square test was employed. According to Tavakoli (2013, p. 59), the Chi-square test compares actual or observed frequencies with expected frequencies in a sample data to decide if the two frequencies differ statistically. It is also employed to examine to investigate the relationship between the variables, which provides the researcher with information on how the variables may influence each other (Tavakoli, 2013; Paltridge \& Phakiti, 2015). This may propose that Chi-square is the suitable data analysis instrument in the present study, since it aims to decide whether the English proficiency level of the participants influences their production of English synonyms.

\section{Results and Discussion}

\subsection{Quantitative Analysis}

The translation test consisted of 12 items designed to test the ability of 40 Saudi EFL learners to produce the correct synonym in contextualised sentences in English (see section 3.2). The ALs and ILs were asked to provide a translation in English to the Arabic sentences containing the synonyms. A Chi-square test was conducted to determine whether the ALs had more correct answers than the ILs. This test can reveal whether the English proficiency level of the two groups had an impact on their ability to produce the correct English synonyms; thus, answering the third research question: the extent to which the English proficiency level of Saudi EFL learners affects their production of English synonyms. It can also provide an answer to the second research question: whether the IL learners make more errors in the translation task than the AL learners. Table 1 presents the number of correct answers on each item on the translation test followed by the Chi-square result accompanied by the $P$ value, which shows whether the ALs had significantly more correct responses than the ILs.

Table 1. The number of correct answers on each item and the results of the Chi-square on the translation test

\begin{tabular}{llll}
\hline No. & Item on the test & Intermediate learners (ILs) & Advanced learners (ALs) \\
\hline 1. & Fast car & 11 & 13 \\
2. & Absolutely exhausted & 3 & 5 \\
3. & Extremely cheap & 6 & 7 \\
4. & Completely useless & 7 & 9 \\
5. & Robbed a bank & 4 & 7 \\
6. & High expectations & 10 & 13 \\
7. & Taking a photo & 2 & 5 \\
8. & Commit suicide & 14 & 8 \\
9. & Absolutely delicious & 3 & 15 \\
10. & Under oath & 1 & 6 \\
11. & Guided tours & 3 & 4 \\
12. & Herd of cows & 66 & 8 \\
\hline
\end{tabular}

Note. Chi-square: 6.9639. $P$ value: $0.01(<0.05)$. 
Table 1 shows that the number of correct answers provided by ALs was higher than that provided by ILs on all items. The result of the Chi-square test (6.9639) yielded a $P$ value $(0.01)$ which is less than $(0.05)$, suggesting that the differences between the two groups, as far as the number of correct answers provided by them is concerned, were statistically significant. This indicates that, overall, the English proficiency level of the participants may have played a role in their ability to produce correct synonyms in English. Even though the differences between the two groups on the translation test were statistically significant, the total number of correct answers provided by the two groups, i.e., 66 and 100 out of 240 (the total number of correct answers that should be provided by each group) is still low, which suggests that both groups encountered difficulties in translating synonyms into English. The results on item 1, i.e., number of correct answers 13 and 11 provided by the ALs and ILs respectively, suggest that the ILs could have found this item more difficult in comparison with the ALs. On item 2, Table 1 shows that 3 and 5 of the ILs and ALs were able to provide the correct answer, respectively. The low number of correct answers may suggest that both groups found this item challenging. With regard to items 3 and 4, Table 1 shows that the number of correct answers provided by ALs (7) and ILs (6) on the former and (9) and (7) on the latter was very close. This indicates that the low number of correct answers also suggests that both groups found these items difficult to produce. Table 1 shows that both groups encountered problems with item 5 on the test. The number of correct answers provided by ALs was 7 and that provided by ILs was 4.On item 6, the number of correct answers was slightly better compared to the participants' answers on other items on the test. The number of correct answers provided by ALs was 13 and that supplied by ILs was 10 . This may suggest that a good number of both groups, especially ALs, did not find item 6 particularly difficult to produce. Table 1 also shows that both groups found item 7 difficult to produce. Specifically, the number of correct answers provided by the ALs was 5 , while that provided by the ILs was 2 .Based on Table 1 , item 8 presented a challenge to both groups in general and ILs in particular. The number of correct answers provided by the ALs was 8 and by the ILs 2. The participants in both groups found item 9 quite easy. The number of correct answers provided by the ALs was 15 and that provided by the ILs was 14.Item 10 as shown in Table 1 was found difficult by both groups on the test. The number of correct answers provided by the ALs was 6, whereas that provided by the ILs was 3.Item 11 shows that the participants were not aware of the collocation guided tours. Only 4 of the ALs provided correct answers on this item and only 1 of the ILs provided accurate answers. Finally, Item 12 also elicited a low number of correct answers from both groups, i.e., ALs (8) and ILs (3). In the following section, an account of the participants' results on each item on the translation test is provided and a possible interpretation of the source of error is supplied.

\subsection{Qualitative Analysis}

With regard to item 1, I provide some answers produced by the ILs on this item. Note that the correct translation is: This is a very fast and powerful car. I wish I had enough money to buy it:

1) *This is a quick and strong car. I hope I have money to buy that car.

2) *This is not a slow car, it is a strong car. I have no money to buy it.

The answers provided by the ILs show that they were not familiar with the correct collocation in English, i.e., fast car, providing answers such as quick car (see Martin, 1984). The meaning of fast, based on the Online Cambridge Dictionary (2016) is "moving or happening quickly, or able to move or happen quickly", whereas that of quick is "happening or done with great speed, or lasting only a short time". Both of them have the same primary meaning "with great speed"; yet only fast can be used in combination with cars. However, a big number (9) of the ILs and (7) of the ALs were not aware of the different senses conveyed by the two English adjectives, which made them provide wrong answers on the test. Example (2) shows that Saudi EFL learners may resort to other strategies when they cannot provide the correct synonym. In particular, one of the ILs provided the antonym of the word fast, i.e., slow accompanied by the negator not. This means when the participant finds that he/she is not sure about the correct English synonym that should be provided; he/she opts to avoid answering by providing an antonym with a negator. In his/her mind, he/she provided a correct translation to the sentence, conveying the gist of the meaning. This strategy may show that when an EFL learner is not self-confident about the answer that should be provided, he/she chooses to avoid answering either by leaving the space blank or resorting to another strategy, which shows that he/she understood what was required, yet they were not sure about their answer. This helps in answering the fourth research question: the type of errors produced by Saudi EFL learners.

With regard to item 2, I provide are some answers below produced by both groups on the test. The correct translation is: I'm absolutely exhausted; I worked for 9 hours non-stop: 
3) *I am very tired, I was working for nine hours.

4) *I feel tiring because I work nine ours.

The answers provided by the participants may suggest that they were not familiar with the word exhausted, even though the word exhausted has an equivalent in Arabic, i.e., مرهق. The majority of the participants wrote very tired rather than absolutely exhausted despite the fact that very tired has a different translation in Arabic, i.e., متعب جدا. In other words, L1 may not be the reason for the erroneous responses provided by the participants on the test, since مرهن are distinct words in Arabic as they are in English. One explanation could be that

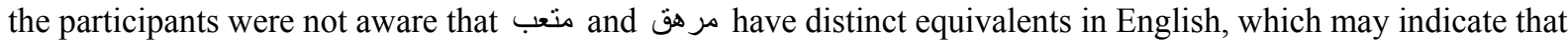
the source of error was intralingual, rather than interlingual. Erdoğan (2005, p. 265) suggests that L2 learners' errors can be divided into two main types: interlingual transfer and intralingual transfer. The former results from L1 interference, whereas the latter is caused by partial learning of L2 (see Saville-Troike, 2012). In this case, the participants had partial learning of English, i.e., they did not know the English word. Another explanation could be that many Saudi EFL learners follow a strategy in which they only learn one synonym in English and use it in all contexts, rather than learning many synonyms which they believe is not necessary, since they all have the same core meaning. This may indicate that many Saudi EFL learners are not aware of the fact that true synonyms which have the same meaning components do not exist. In other words, they may not know that synonyms are only partially similar; thus, not all synonyms are interchangeable.

Example (2) also shows another erroneous response provided by the participants, i.e., feel tiring. This answer, again, shows that the participants are not aware of the difference between tired and exhausted. In this regard, EFL teachers need to explain to the students that learning only one synonym and using it in all contexts is incorrect, since that may cause them to produce marked sentences which native speakers of English never produce. EFL teachers may give students real sentences (collected from a corpus for example) and show them how each synonym is used in certain contexts, not all. This type of tasks can help EFL learners understand the concept of partial synonymy and endeavour to learn how each synonym is used in its context.

Concerning items 3 and 4 , below are some answers provided by the participants on the test. The correct translations of items 3 and 4 are: Sarah bought some extremely cheap shoes at the mall last night and Don't ever ask Philip to help; he is completely useless.

5) Sarah bought very cheap shoes from the mall last night.

6) Sara found cheap shoes in the mall yesterday.

7) Sarah bought too cheap shoes from the mall last night.

8) Don't ask phelip to help you because he is very useless.

9) Do not ask filib to help you. he is not helpful.

The answers provided by the participants suggest that they are not aware of the collocation extremely cheap. Example (5) shows that some participants opted for using very instead of extremely. In fact, many participants produced very instead of extremely on the test. One possible interpretation for their answers is that in Arabic, جد "very" without affecting the meaning at all. This lack of difference is reflected in the answers provided by the participants on the test (see Table 1). Thus, whenever Arabic-speaking EFL learners want to add emphasis on an adjective or an adverb in English, they use very which is a literal translation of جery can be used in the context provided on the test, i.e., very cheapshoes, but it may not be suitable in other contexts, e.g., fully aware vs. *very aware. Hence, the erroneous responses supplied by the participants in this case can be attributed to L1 interference, where the participants translated an adverb directly from Arabic (see the fourth research question). In example (6), the participants chose not to provide an adverb at all. This could be due to the fact that the participants may not have read the sentence carefully during the test, or they have read it but did not know which word corresponded to للغاية "extremely" in English. Thus, they opted for not providing an answer at all. Even though the adverb extremely has a distinct equivalent in Modern Standard Arabic (MSA), many participants were not able to provide the correct adverb, since the different nuances of meaning conveyed by intensifying adverbs in spoken Arabic can be all captured by جدا "very", especially as far as SA is concerned. The differences between these adverbs are clearer in MSA. Thus, it can be argued that the participants' L1 may have affected their answers on the test, regardless of the fact that they have studied MSA since they were in the first grade.

Example (7) shows that the participants who provided that answer are not aware of the difference between very and too in English. Unlike very, too is used before an adjective or adverb to emphasize a negative meaning. However, the participants who provided too on the test were not aware of this difference. Again, it seems that 
Saudi EFL learners are not familiar with the different nuances of meaning between synonyms in English, thus, they produced semantic errors (see the fourth research question). Example (8) shows, again, that some participants used the strategy "not + antonym", suggesting that this strategy could be frequent as far as Arabic-speaking EFL learners are concerned.

Regarding item 5, below are some answers provided by the participants on this item. The correct translation is Three guys robbed a bank yesterday and the police is still looking for them.

10) 3 men stole the bank yesterday. The policemen are searching for them.

11) Three theif men stole the money from the bank with guns and the police are looking for the men.

The answer provided in example (10) was the most common answer produced by both groups. Their answers suggest that they are not aware of the difference in meaning between steal and rob. To convey the meaning "take something that does not belong to you without permission", many Saudi EFL learners used the verb steal. Despite the fact that the two verbs, steal and rob, have distinct equivalents in MSA, i.e., سطى and wa and the participants did not know the equivalent of سطى "rob" in English. Therefore, they provided another verb that they are familiar with and it conveys the core meaning of the verb rob. This is, again, an intralingual type of error, where the participants are not aware of a specific word in the target language (cf. Erdoğan, 2005). Example (11) shows that the participant who provided the answer stole with guns was aware of the fact that steal on its own does not suffice, since steal does not imply the use of a weapon. Thus, the participant provided the prepositional phrase with guns to convey the meaning. This answer was provided by an AL, rather than IL, which suggests that a higher English proficiency level can enable the EFL learner to be more sensitive to different nuances of meaning (see the third research question).

On item 6, one of the main reasons for the participants' slightly better performance (i.e., compared to other items) is that the adjective which the participants were asked to provide an English equivalent for has only one translation, i.e., high. In other words, if the participants are familiar with the word high in English, it is the only correct answer that can be provided, since it has a very distinct meaning that cannot be substituted by other words either in MSA or SA. The participants that were not familiar with the word high provided intensifying quantifiers/adjectives, such as a lot of, many, several, big number of, great expectations or they did not provide an equivalent at all. The participants who provided great expectations could have been influenced by the novel by Charles Dickens, since they have studied it at the University. Here, it can be suggested that the participants may not have been familiar with the collocation of high + expectations in the context of the sentence provided on the test. That is, they literally translated the word عالية "high" into English and the answer happened to be correct.

With respect to item 7, the main reason behind the low number of correct answers provided by the participants was that a big number of the participants from both groups literally translated the verb biتt "capture" from Arabic into English, providing answers such as capturing a photograph. This answer suggests that the participants' L1 may have had a direct impact on their answers on this item. The participants may not have been familiar with the combination of take + photo. Some participants provided the verb photograph instead. Lack of exposure to real-life English data could be responsible for the lack of awareness of many Saudi EFL learners of English collocations. Taking into consideration that most material they are exposed to at school and University are made-up sentences, which may not be used by native speakers of English on a daily basis, Saudi EFL learners are not aware of the contemporary real-life English language used by native speakers. In addition, based on my experience as a teacher of English, the focus in Saudi curricula as far as English teaching is concerned is on syntax and sentence structure. Little attention is given to areas such as synonymy and collocations.

Concerning item 8 , the main reason behind such poor performance can be attributed to the fact that commit suicide can be expressed in Arabic using only one verb, i.e., ينتحر "commit suicide". Thus, many participants from both groups produced only suicide without commit, believing that it can be used as a verb on its own. Their answers reflect their lack of awareness of the correct equivalent in English, i.e., commit suicide and a lack of awareness of parts of speech in English. Thus, one may argue that this type of error can be caused by a combination of interligual and intralingual errors (see the fourth research question). In this regard, teachers of English as a second or foreign language need to acquaint students with the fact that one-to-one equivalence between English and Arabic may not be possible all the time. The two languages have different lexical items that could be expressed using one word only or sometimes many words. This type of knowledge may help EFL learners produce unmarked sentences in English, since they will not be under the impression that what applies to L1 applies to L2 all the time.

With regard to item 9, the reason why the participants found this item easy was because they are familiar with the equivalent of شهياً in English which is delicious. All they had to do was literally translate the word from 
Arabic, providing the correct answer. Another reason could be that this lexical item is important to learn, since it conveys an important concept in day-to-day activities. Thus, the participants from both groups were familiar with it.

With respect to item 10 , the main reason behind the poor performance by both groups could be ascribed to the fact that they were not familiar with the word oath. Most participants from both groups provided the word swear, which is not suitable in the context provided on the test. Again, the unwillingness of Saudi EFL learners to learn synonyms is clear here as well. They may have been under the impression that learning the word swear is enough and can be used in all contexts.

Regarding item 11, it appears that collocational errors are the most common type of errors as far as the acquisition of synonymy by Saudi EFL learners is concerned. The participants from both groups provided answers such as trips for tourism, tourism journey, a trip with a touristic guide, picnic, etc. Their answers clearly reflect a lack of awareness of the correct collocation to be used with tour.

On item 12, again, the main reason behind the poor result could be attributable to the fact that the participants were not familiar with the word herd. Many participants from both groups produced answers such as a group of cows, a cow flock, a number of cows, etc. Their answers show that they may not be aware of the different words used to describe a group of animals in English, i.e., herd, swarm, flock, school and pack. The errors could also be ascribed to the influence of L1, where the distinction between the above words is non-existent. That is, in Arabic, there are no differences between herd and pack, both of them are rendered as قطيع. Moreover, there are no differences between flock, swarm and school, all of them can be translated as سربع. This lack of difference between these words in Arabic affected their acquisition by Saudi EFL learners.

\subsection{Discussion}

Based on the data analysis, it appears that both groups encountered problems in producing synonyms in English. Even though the overall differences between the two groups were statistically significant, the number of correct answers provided by both groups was low. The participants' L1 played a big role in their erroneous answers on the test; hence, providing an answer to the fourth research question. Their lack of awareness of some lexical items in English as well as some collocations also contributed to their faulty answers on the test.

In addition, the number of correct answers provided by ALs was higher than that provided by ILs on all items and the differences were statistically significant. This indicates that the English proficiency level of the participants may have played a role in their ability to produce correct synonyms in English. However, the performance of both groups was still generally poor on the translation test. This confirms the results of Laufer's (1991) study, who posits that even advanced learners encounter difficulties when dealing with synonyms in L2, since they employ the same word to convey the same concept over and over again. Alrishan \& Smadi (2015) also indicate that even advanced Arabic-speaking EFL learners encounter difficulties with the translation of lexical items. The main sources of errors on the translation test in the current study were: (1) lack of familiarity of the correct collocation in English; (2) lack of knowledge of some English lexical items; (3) L1 interference; (4) the fact that many Saudi EFL learners are not aware of the fact that true synonyms which have the same meaning components do not exist; (5) lack of exposure to real-life English sentences; and (6) lack of focus on the acquisition of vocabulary in schools in Saudi Arabia. The data analysis also shows that many Saudi EFL learners may resort to other strategies when they cannot provide the correct synonym. Specifically, they avoid answering by providing an antonym with a negator, instead of the synonym. This strategy was not discussed in the relevant literature, to the best of my knowledge, which suggests that more studies are needed in this area to examine whether this strategy is exhibited cross-linguistically or it is exclusive to Saudi or Arabic-speaking EFL learners. This investigation can provide more insight on the effect of L1 on the acquisition of synonyms in English. In general, the translation test was found to be difficult.

Based on the results of translation test, one may suggest that direct instruction can yield better results than incidental learning in relation to the production of synonyms by Saudi EFL learners (Sadoski, 2005; Lyster, 2007). This proposalis in disagreement with that of Krashen (2004), who posits that vocabulary should be acquired indirectly or incidentally through extensive reading. Krashen's (2004) idea is put forward on the basis of the input-oriented language acquisition theory, indicating that if the input is meaningful and contextualised, then the learner is able to connect the meaning with the form (see also Min, 2008). Yet, the answers supplied by Saudi EFL learners on the translation test may propose that the semantic differences synonyms, the means by which each synonym should beutilised in particular contexts and the observation that there are differences between L1 and L2 related to lexical items need to be explained directly to the students. Hence, one may suggest that incidental learning (together with direct instruction) is potentially more useful with advanced EFL learners. 
However, this type of learning may not be useful with low or intermediate learners (see Schmitt, 2008). The latter group may not pay attention to the semantic difference between synonyms unless the teacher indicates that difference directly.

\section{Conclusion}

This study has examined the productive skills of 40 Saudi EFL learners pertaining to English synonyms through employing a translation test. It has also investigated whether the participants' English proficiency level can influence their answers on the test. The results demonstrate that even though the participants' results were generally poor, the number of correct answers provided by the advanced learners (ALs) was higher than that provided by the intermediate learners (ILs), suggesting that the English proficiency level may have played a role in the participants' results. The most common sources of error produced on the test were: (1) lack of familiarity of the correct collocation in English; (2) lack of knowledge of some English lexical items; (3) L1 interference; (4) the fact that many Saudi EFL learners are not aware of the fact that true synonyms which have the same meaning components do not exist; (5) lack of exposure to real-life English sentences; and (6) lack of focus on the acquisition of vocabulary in schools in Saudi Arabia. Based on these results, it is recommended that studies that focus on the acquisition of vocabulary by EFL learners are needed to shed light on the semantic, syntactic, morphological and stylistic difficulties encountered by these learners when dealing with different lexical and morphological phenomena in English. Studies that tackle different properties of syntactic and morphological language structures (see Altakhaineh, 2016) can make the acquisition of these structures easier.

\section{References}

Albert, M. L., \& Obler, L. K. (1978). The Bilingual Brain: Neuropsychological and Neurolinguistic Aspects of Bilingualism. New York: Academic press.

Alharthi, T. (2014). Role of vocabulary learning strategies in EFL learners' word attrition. International Journal of English Language and Linguistics Research, 2(3), 13-28.

Alotaibi, A. (2014). The comprehension of English lexical collocations by Kuwaiti EFL learners. International Journal of English Language and Linguistics Research, 2(3), 1-12.

Alrishan, A., \& Smadi, O. (2015). Difficulties EFL Jordanian university students encounter in translating English idioms into Arabic. Journal of Education and Practice, 6(10), 124-133.

Altakhaineh, A. R. M. (2016). Headedness in Arabic compounds within the synthetic genitive Construction. SAGE Open, 6(4), 1-16. https://doi.org/10.1177/2158244016674514

Altakhaineh, A. R. M., \& Rahrouh, H. (2015). The use of euphemistic expressions by Arab EFL learners: Evidence from Al Ain University of Science and Technology. International Journal of English Linguistics, 5(1), 14-21. https://doi.org/10.5539/ijel.v5n1p14

Altakhaineh, A. R. M., \& Zibin, A. (2014). Perception of culturally loaded words by Arab EFL learners. International Journal of Linguistics, 6(3), 1-22. https://doi.org/10.5296/ijl.v6i3.4922

Beardsmore, H. B. (1982). Bilingualism: Basic principles. Avon: Tieto.

Cambridge Online Dictionary. (2016). Retrieved from http://dictionary.cambridge.org/

Coady, J. (1993). Research on ESL/EFL vocabulary acquisition: Putting it in context. In T. Huckin, M. Haynes, \& J. Coady (Eds.), Second Language Reading and Vocabulary Learning (pp. 3-23). Norwood, NJ: Ablex Publishing.

Corpus of Contemporary American English (COCA). (2016). Retrieved from http://corpus.byu.edu/coca/

Cruse, D. A. (1986). Lexical Semantics. Cambridge: Cambridge University Press.

Dechert, H. W. (1983). How a story is done in a second language. In C. Faerch \& G. Kasper (Eds.), Strategies in Interlanguage Communication. London: Longman.

Dordick, M. (1996). Testing for a hierarchy of the communicative interference value of ESL errors. System, 24, 299-308. https://doi.org/10.1016/0346-251X(96)00023-1

Edmonds, P., \& Hirst, G. (2002). Near-synonymy and lexical choice. Computational Linguistics, 28(2), 105-144. https://doi.org/10.1162/089120102760173625

Engber, C. A. (1995). The relationship of lexical proficiency to the quality of ESL compositions. Journal of Second Language Writing, 4, 139-155. https://doi.org/10.1016/1060-3743(95)90004-7

Erdoğan, V. (2005). Contribution of Error Analysis to Foreign Language Learning. Mersin University Journal of 
the Faculty of Education, 1, 261-270.

Gove, P. B. (1984). Webster's New Dictionary of Synonyms. Springfield, MA: Merriam-Webster.

Hatch, E., \& Brown, C. (1995). Vocabulary, Semantics, and Language Education. Cambridge: Cambridge University Press.

Hu, M., \& Nation, P. (2000). Vocabulary density and reading comprehension. Reading in a Foreign Language, $13(1), 403-430$.

Krashen, S. (2004). The Power of Reading. Englewood, CO: Libraries Unlimited.

Laufer, B. (1991). Ease and difficulty in vocabulary learning: Some teaching implications. Foreign Language Annals, 23(2), 147-155. https://doi.org/10.1111/j.1944-9720.1990.tb00355.x

Lightbown, P., \& Spada, N. (1999). How Languages are Learned (2nd ed.). Oxford: Oxford University Press.

Liu, D. (2013). Salience and construal in the use of synonymy: A study of two sets of near synonymous nouns. Cognitive Linguistics, 24, 67-113. https://doi.org/10.1515/cog-2013-0003

Liu, D., \& Zhong, S. (2014). L2 vs. L1 use of synonymy: An empirical study of synonym use/acquisition. Applied Linguistics, 1-24.

Lyster, R. (2007). Learning and Teaching Languages through Content: A Counterbalanced Approach. Amsterdam/Philadelphia: John Benjamins. https://doi.org/10.1075/11lt.18

Martin, M. (1984). Advanced vocabulary learning: The case of synonyms. Modern Language Journal, 68, 130-137.

Min, H. (2008). EFL vocabulary acquisition and retention: Reading plus vocabulary enhancement activities and narrow reading. Language Learning, 58(1), 73-115. https://doi.org/10.1111/j.1467-9922.2007.00435.x

Nation, P., \& Waring, R. (1997). Vocabulary size, text coverage and word lists. In N. Schmitt \& M. McCarthy (Eds.), Vocabulary: Description, Acquisition and Pedagogy (pp. 6-19). Cambridge: Cambridge University Press.

Paltridge, B., \& Phakiti, A. (2015). Research Methods in Applied Linguistics: A Practical Resource. London: Bloomsbury Publishing.

Quine, W. V. (1951). Two Dogmas of Empiricism. Philosophical Review, 60, 20-43. https://doi.org/10.2307/2181906

Sadoski, M. (2005). A dual coding view of vocabulary learning. Reading \& Writing Quarterly, 21, 221-238. https://doi.org/10.1080/10573560590949359

Saeed, J. (2003). Semantics (3rd ed.). Oxford: Wiley Blackwell.

Saville-Troike, M. (2012). Introducing Second Language Acquisition (2nd ed.). Cambridge: Cambridge University Press. https://doi.org/10.1017/CBO9780511888830

Schmitt, N. (2008). Instructed second language vocabulary learning. Language Teaching Research, 12(3), 329-363. https://doi.org/10.1177/1362168808089921

Tavakoli, H. (2013). A Dictionary of Research Methodology and Statistics in Applied Linguistics. Rahnama Press.

Webb, S. (2007). The effects of synonyms on second language vocabulary learning. Reading in a Foreign Language, 19(2), 120-136.

Yamashita, J., \& Jiang, N. A. (2010). L1 influence on the acquisition of L2 collocations: Japanese ESL users and EFL learners acquiring English collocations. TESOL Quarterly, 44(4), 647-668. https://doi.org/10.5054/tq.2010.235998

Yeh, Y., Liou, H., \& Li, Y. (2007). Online synonym materials and concordancing for EFL college writing. Computer Assisted Language Learning, 20, 131-152. https://doi.org/10.1080/09588220701331451

Zibin, A., \& Altakhaineh, A. R. M. (2016). Acquiring the English causative alternation: Evidence from the University of Jordan. International Journal of Applied Linguistics and English Literature, 5(3), 7-15. 


\section{Appendix A}

\section{Translation Test}

Translate the following sentences into English (the participants should provide the following translations in English).

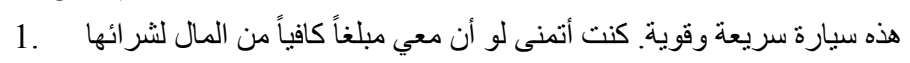

This is a very fast and powerful car. I wish I had enough money to buy it.

2. أنامر هقتتماماً. لقدعملتتسعساعاتمتو اصلة

I'm absolutely exhausted; I worked for 9 hours non-stop.

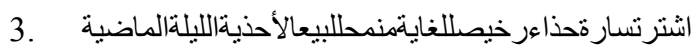

Sarah bought some extremely cheap shoes at the mall last night.

4. لاتطلبمنفيليبالمساعدةأبدأفهو عديمالفائدةثماماً

Don't ever ask Philip to help; he is completely useless.

5. امثثاثثشبانبالسطو المسلحعلبنكالبارحةو لاتز الالثرطةتبحثنهم

Three guys robbed a bank yesterday and the police is still looking for them.

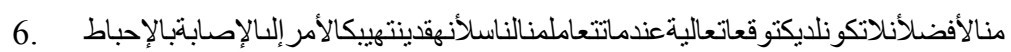

It is better not to have high expectations when it comes to people, because you may end up getting disappointed.

7. منفلك، هلتسنطيعأنتلتقطصورةليو لصديقي؟

Excuse me, would you mind taking a photo of me and my friend?

8. يعتبر الاكثئابمنالأسبابالرئيسية/التيتدفعالناسلانتحار

Depression is one of the main reasons that drive people to commit suicide.

9. الطبقالذيأعنتهناسوز انالبارحةكانشهياًجداً

The meal Susan cooked for us yesterday was absolutely delicious.

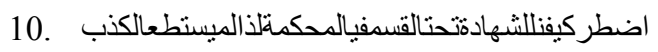

Kevin was made to testify under oath at the court, so he couldn't lie.

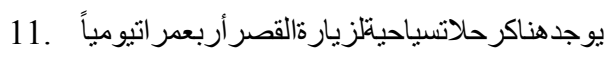

There are guided tours of the palace four times daily.

12. فيطريقيإلالمزر عة،ر أيتقطيعاًَنالأبقار متجمّعةعندنبعالماء

On my way to the farm, I saw a herd of cows gathered around a water stream.

\section{Copyrights}

Copyright for this article is retained by the author(s), with first publication rights granted to the journal.

This is an open-access article distributed under the terms and conditions of the Creative Commons Attribution license (http://creativecommons.org/licenses/by/4.0/). 